Chronicling Engagement: Students' experience of online learning over time

Authors:

Tracey Muir

Naomi Milthorpe

Cathy Stone

Janet Dyment

Elizabeth Freeman

Belinda Hopwood

University of Tasmania, Launceston, Tasmania, Australia

Corresponding author: Tracey.Muir@utas.edu.au 


\title{
Chronicling Engagement: Students' experience of online learning over time
}

\begin{abstract}
While there is ample research into student engagement in online learning, much of this investigates the student experience through surveys administered at a fixed point in time, usually at the exit point of a single unit of study or course. The study described in this paper, by contrast, aimed to understand online student engagement over a whole semester, guided by two overarching questions: What factors impact students' engagement over a semester? What factors account for fluctuation in engagement levels over time? This paper presents results from weekly feedback on online education students' engagement over the length of one semester at a regional Australian university. It also chronicles in more depth the experiences of one such student, 'Angela', across the same semester. The findings offer longitudinal accounts of student engagement, demonstrating that levels of engagement fluctuate and are influenced by a variety of factors.
\end{abstract}

Keywords: engagement; online initial teacher education; flexibility; online education; mature-age students.

\section{Introduction}

The growth of online education in the Australian tertiary sector over the past decade (Australian Government Department of Education \& Training [DET], 2017a) has opened the doors of higher education to a wider, more diverse student cohort. Students from backgrounds historically under-represented in Australian higher education - such as those from lower socio-economic status (SES) backgrounds, students with disability, those from regional and rural areas of Australia, and Australian Indigenous students (Aboriginal and Torres Strait Islanders) - are more strongly represented in online enrolments than in oncampus, face-to-face modes of study (Stone, 2017). This is particularly the case within undergraduate degrees offered entirely online, with no or little face-to-face attendance required. The majority of undergraduate, online students are also mature-aged and combining their studies with work and family responsibilities 
(Hewson, 2018; Michael, 2012; Ragusa \& Crampton, 2018; Signor \& Moore, 2014; Stone, O’Shea, May, Delahunty \& Partington, 2016). Many are also first within their families to attend university (Stone \& O’Shea, 2013).

While the number of external students in Australian higher education is now rising faster than those studying on-campus (DET, 2018, p. 14), the retention rate is less positive (Greenland \& Moore, 2014), with evidence that external students in Australia are two and a half times more likely than on-campus students to withdraw without a qualification (DET, 2017b). A recent Australian report into improving outcomes in online higher education (Stone, 2017) points to the importance of regular, constructive communication with students, particularly “establishing a strong teacher-presence” (p. 36). It also highlights the importance of course design "that engages and connects students with their teacher, other students and the course material” (p. 39), and in which support for students, including technology support, is embedded. These findings echo other research that has highlighted both the importance of teacher communication with students (Lambrinidis, 2014; Vincenzes \& Drew, 2017) and ensuring course design and delivery are interactive and engaging (Devlin \& McKay, 2016; Park \& Choi, 2009).

\section{Review of the literature}

\section{Engagement}

Engagement is a multifaceted concept that encompasses behavioural, emotional and cognitive aspects (Fredericks, Blumenfeld, \& Paris, 2004). Behavioural engagement refers to participation and includes involvement in academic, social or extracurricular activities. Emotional engagement encompasses affective reactions to teachers, classmates and the institution in which the learning occurs. Finally, cognitive engagement incorporates thoughtfulness and willingness to exert the effort to comprehend subject matter and master skills (Fredericks, et al., 2004). In the online learning context, Kuh (2001) has identified dimensions of engagement including level of academic challenge, active and collaborative learning, student-faculty interaction and enriching educational experiences. A study evaluating online experiences of students in the United States (Robinson \& Hullinger, 2008) found that all Kuh's (2001) dimensions influenced student engagement and that levels of engagement varied among age groups. Mature 
aged students ( $>25$ years), for example, worked harder to meet expectations, participated more in collaborative projects and contributed more to online discussions. Engagement has also been linked with academic emotions (e.g., Pekrun \& Linnenbrink-Garcia, 2012), and seen as a mediator between students’ emotions and their achievement. Engagement was also found to occur along a continuum, indicating that just as emotions fluctuate, engagement will also fluctuate over time. As engagement is both dynamic and situational, survey instruments that are often administered at a single point in time are limited in capturing the complexity of the construct (Kahu, 2013). Our research adopts a holistic perspective which is not measurable by one-off surveys but best understood through in-depth qualitative work (Kahu, 2013).

Engagement in online learning

A review of the literature revealed a number of inherent challenges in studying successfully online. The convenience factor of studying online can be diminished by technical problems, lack of interaction with tutors and other students, problems with instructional materials, and students’ own difficulties with time management (Ilgaz \& Gülbahar, 2015). Students have expressed experiencing feelings of alienation, perceived lack of relevance, and the drudgery of study (Wimpenny \& Savin-Baden, 2013) as influencing online engagement. For many older students, with work and family responsibilities, there is evidence that "work-related factors" and "personal reasons relating to health and family commitments” (Greenland \& Moore, 2014, p. 53) can also impact upon engagement and significantly contribute to attrition.

There is a considerable body of research demonstrating that for online learners, particularly from non-traditional backgrounds, "social presence... is vital to creating a learning environment conducive to students feeling connected to each other and their respective tutors” (Lambrinidis, 2014, p. 257). The 'presence' of the online teacher/instructor is vital for building interaction and connectedness between teacher and student, and student and student. Ragusa and Crampton (2018) found that "the quality and timeliness of lecturer feedback was the most valued form of learning communication identified by students regardless of course” (p. 15). There is much discussion in the literature about practical ways to achieve this, including synchronous and asynchronous interactions, through discussion boards, blogs, chat rooms, wikis and social media; creative use of video, audio-clips and vignettes; assessment tasks that are paced, scaffolded and 
provide prompt, constructive feedback; both individual and small group work, well facilitated; and matching technology to the task (e.g., Boton \& Gregory, 2015; Lambrinidis, 2014).

Moore (1993) described three interaction categories that foster student engagement: learner-learner, learner-instructor, and learner-content. Martin and Bolliger (2018) found that learners most valued learner-instructor engagement strategies, and perceived a sense of belonging when they could interact with instructors who were accessible through multiple means. Consistent instructor presence was considered the most valued engagement strategy (Martin \& Bolliger, 2018). As Wimpenny and Savin-Baden (2013) found, an academic's style and approach can adversely affect student engagement, with some students being made to feel an "inconvenience" as a result of staff responses.

Taking these factors into consideration, the research discussed in this paper aimed to answer the following research questions: What factors impact upon students' engagement over a semester? What factors account for fluctuation in engagement levels over time? This paper presents the results from students' weekly feedback and chronicles the experiences of one student, 'Angela', as an individual case study of a student studying a Bachelor of Education degree, fully online, at an Australian regional university. Through an in-depth analysis of one student's online experience, a longitudinal account of engagement over the length of one full semester emerges. Patterns of engagement (and disengagement) which emerge from this student's story have implications for the ways in which educators can support online students to persist with their studies.

\section{Methodology}

We took an interpretive qualitative approach to the research design, in order to understand in depth the students' engagement with learning online, and to explore those experiences that may be multi-layered, complex and "as varied as the situations and contexts supporting them” (Cohen, Mannion, \& Morrison, 2011, p. 18).

Student participants were recruited from a School of Education at an Australian regional university, following formal ethical approval from that university. All were enrolled in their third year of a four-year Education degree. The degree was offered in three modes: fully on-campus, fully online, or mixed mode. Online delivery was provided through the University’s Learning Management System 
(LMS) and typically consisted of recorded lectures, prescribed readings, online learning content and activities, 2-3 assessment tasks and discussion boards. We adopted a purposeful approach to sampling (Creswell, 2012) and chose to recruit students who were nominated by previous lecturers as 'engaged learners', who would 'stay the course' and not withdraw from study. To help identify potential participants, an engaged online learner was described as someone who: consistently and reliably participated in discussion forums or other learning activities; collaborated with other students; and engaged with the lectures/readings. Participant study load varied from 50\% of a full-time load (two units of study) to $100 \%$ (four units of study), with some studying a $75 \%$ load (three units of study).

To gain a clear understanding of student engagement over time, this study adopted a prospective longitudinal method (Cohen, et al., 2011), which allowed for student input at multiple points in time across a 13-week semester. This approach aimed to identify factors that influenced engagement in the online space over time, and to provide more opportunities to "catch the complexity" underpinning student behaviour in response to their studies (Cohen, et al., 2011, p. 266). In doing so, it adds to the existing literature which tends to capture student voice through survey instruments often at exit points, rather than over a sustained period of time (e.g., Ilgaz \& Gulbahar, 2015; Park \& Choi, 2009; Ragusa \& Crampton, 2018).

Study participants were asked to complete a weekly questionnaire, administered via Survey Monkey, that sought to capture their experiences throughout the 13week semester. Bearing in mind the limitations of using surveys to capture the complexity of engagement, for the purpose of this paper we have focused on students' responses to two open-ended questions: "Describe positive/negative things your online lecturers did that influenced your engagement" and "Describe any things that might be affecting your engagement in your studies (e.g., have you been sick? Lots of work? Lots of assignments?)."

To gain rich accounts of online student engagement over time, we also collected data using semi-structured interviews (Hatch, 2002). Our team developed interview schedules through guidance from educational research texts such as Creswell (2012) and Cohen, et al. (2011), and research related to online teaching and learning in higher education (e.g., Bolliger \& Wasilik, 2009; Crawford \& 
Jenkins, 2017; Gannon Cook, Ley, Crawford, \& Warner, 2009). Open-ended questions covered key themes with additional optional prompting questions to delve more deeply into the experience of participants. Illustrative questions included: "Were there any learning activities this week that were a) very rewarding and helped you stay engaged or b) challenging in a negative sense and made it difficult to stay engaged?" and "If you had advice to give to the lecturer this week to promote engagement, what might you offer?”. Students were encouraged to narrate from their own personal perspective (Hollway \& Jefferson, 2000), providing "stories that reveal truths about human experience" (Riessman, 2008, p. 10). Eight interviews were conducted with each student: one before the semester began (“pre-semester interview”); six fortnightly during semester (“during semester interview”); and one follow-up after semester ("postsemester"). Collated interview data from participants are reported elsewhere (under review), but we have selected Angela's interview data to present her 'story' as detailed later in the paper.

Interviews were conducted by a member of the project team by audio or video calls, and ranged between 15 and 30 minutes. Each interview was verbatim transcribed and the transcripts were initially read through by the research team to gain a general sense of the main themes. The process of moving from transcribed accounts to research data involved thematic analysis that employed both deductive and inductive coding. Deductive themes - such as engaging factors, disengaging factors, attributes/skills necessary for online study, and so on - were informed by previous research into online teaching and learning in higher education and teacher education. Inductive themes that emerged from the data, such as notions of flexibility in the online space, are reported on below, in the results and discussion. These steps of data analysis are consistent with Creswell's (2012) steps for analysing and interpreting qualitative data. Following this initial analysis, data were imported into NVivo and assigned codes. Nodes/child-nodes were created to reflect the inductive and deductive themes. In total there were 23 nodes and 37 child-nodes with a total of 5,000 references taken from the data. The node with highest number of references was "Lecturer Communication" ( $\mathrm{n}=114$ from 42 sources), followed by "Relevant/Authentic activities" which had 91 references from 40 sources.

Students' real names were replaced with pseudonyms in all documentation and are used consistently in the results and discussion below. 


\section{Results}

In order to provide a snapshot of how students' engagement fluctuated over the course of a semester, the first part of this section looks at students' responses to the survey, with a particular focus on their responses to two open-ended questions about the factors influencing their engagement. The survey required students to rate their level of engagement for that week on a scale of 1-10 (with 1 being 'not engaged at all', 5 being 'engaged enough' and 10 being 'totally engaged'). They were asked whether or not their units were equally engaging (Yes/No), with the choice to provide an additional open-ended response.

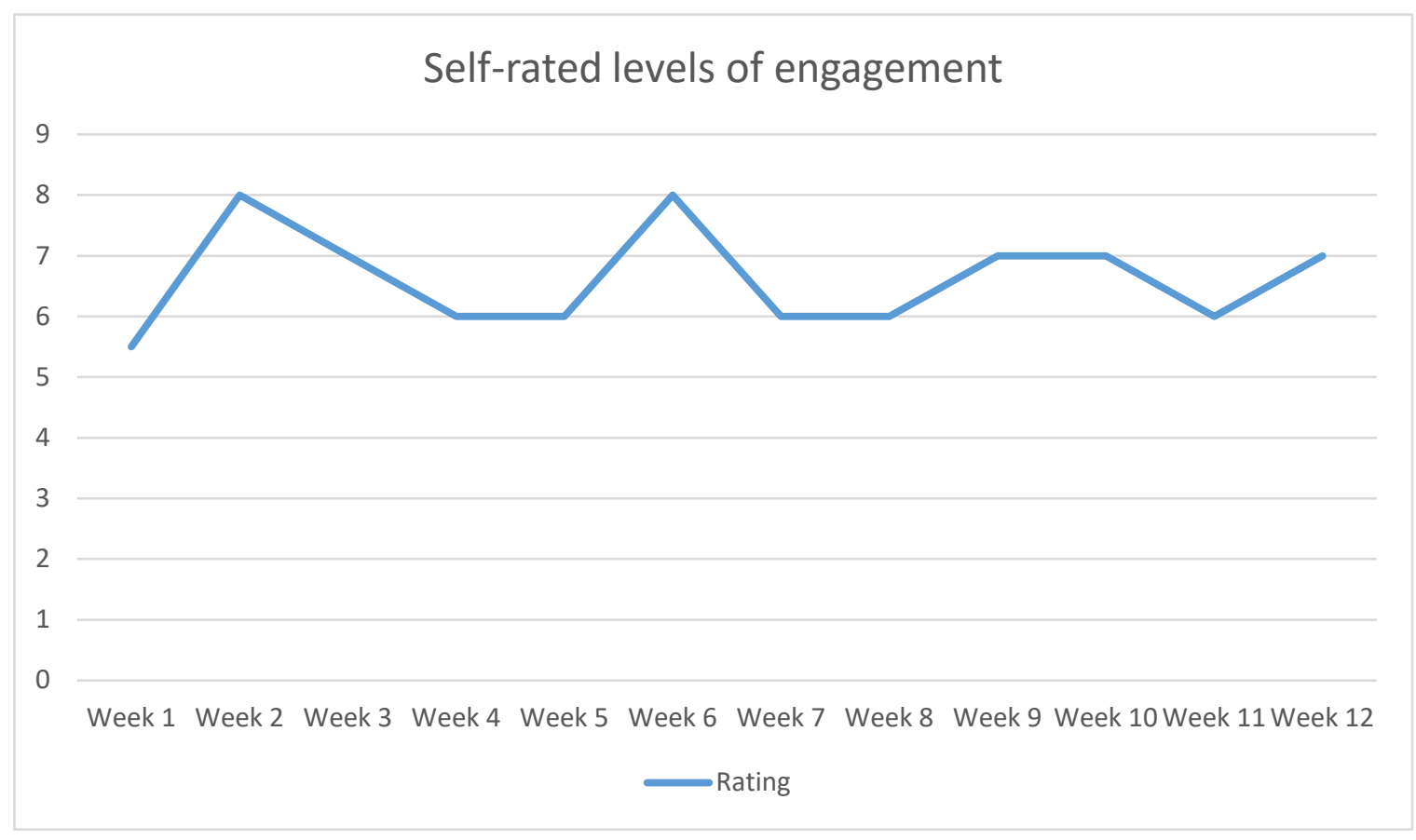

Figure 1. Students' ratings of engagement levels over 12 weeks of semester

Figure 1 shows that students' cumulative ratings of their engagement levels fluctuated across the semester. The lowest levels of engagement were recorded in week 1 (qualitative comments indicate this was influenced by some units not having commenced). In week 1, only two students indicated that they were equally engaged in all their units, with five responding negatively. Weeks 4, 5, 7, 8 and 9 all recorded engagement levels of 6, which was the next lowest. Analysis of qualitative comments for those weeks $(n=19)$ showed that engagement was 
influenced primarily by assessment tasks (12 comments), unit/s workload (4), relevance (2) and lecturer input (1). The highest levels of engagement were recorded for weeks 2 and 6 . Interestingly both these weeks followed a break (some units did not commence until week 2 and week 6 followed Easter).

\section{Influencing factors}

Results from the open-ended survey questions showed that assessment, unit workloads, nature of the units (including relevance), lecturer presence and work/life commitments were all named as factors that influenced individual weekly engagement. The following comments are illustrative of the responses received in relation to each of these factors.

\section{Assessment}

The units with assignments due sooner have engaged my interest the most [Evan, week 2]

I have been busy trying to complete an assignment for one of the units, and not spent any time on the other unit at all [Sonia, week 7]

I feel at this point in the semester I am no longer engaged. I am just trying to get all my assessment tasks completed and engaging only enough to get the information I need to do this [Carol, week 8]

I have assignments due, so those units are the most engaging out of necessity [Julie, week 9]

Trying to get all my assessments done - it feels a little like the learning has stopped and everything is just about assessment tasks [Penny, week 11]

Workload across units

Workload across units was also a factor, particularly in terms of students' consideration of whether or not their units were equally engaging. Penny, for example, commented that "have fallen behind - trying to catch up" [Penny, week 
4], while Margaret felt "Overwhelmed with the workload of three subjects!"

[Margaret, week 1].

Nature of the units

Students indicated that they were more likely to be engaged if they found the content "interesting” [Carol, week 2] and if lecturers provided material relevant to the profession; students frequently compared interesting units with those that were less engaging:

Mostly [engaging] - some units are drier than others [Linda, week 2]

In one of the units I felt the [lecturer] gave a better range of ways to develop our thinking about the topic by presenting videos, interviews and reading materials [Sonia, week 3]

one online tutorial is particularly boring and into the future I may not continue to devote time to this learning activity and use my time more productively completing assessment tasks [Fiona, week 3]

[unit] had a series of interviews about parent-teacher interviews. [...] I learnt more listening to them talk about their experiences than 20 journal articles could have provided [Fiona, week 5]

Lecturer presence

Students evaluated the impact of the lecturer upon their engagement. Positive comments referred to lecturer support, such as providing webinars explaining assessment expectations, and varying the content and presentation of subject matter. Students were explicit on the ways negative lecturer behaviours impacted their engagement:

Failure to engage by the lecturer makes stepping up to one unit very difficult ... why should I be bothered if the lecturer can't? [Sonia, week 5] 
Asked for further feedback on assignment submitted ... and was told no it wasn't possible. Not sure how not aiding someone who wants to learn and do better is in the best interests of education [Julie, week 9]

Work/life commitments

Work/life commitments and events played a role in students' capacity to remain engaged with their studies, as the following comments demonstrate:

Still not 100\% well and I've had a few medical appointments so that's having an impact, as well as my Dad's health not being great, so it's a bit stressful [Linda, week 3]

I have been very busy with my work outside of uni and so I have been trying to play catch up. I haven't engaged as much in uni work as a whole [Sonia, week 5]

Influences across semester

In terms of looking for patterns in responses across the semester, some weeks did share commonalities. For example, in weeks 6, 7 and 8 feedback regarding the influence of assessment tasks on engaging equally with all units was common. Likewise, students’ comments indicated a lack of interaction with discussion boards in weeks 10, 11 and 12 as assessment tasks were due.

This section has looked at the nine participants' self-reporting of their engagement over the course of a semester. The next section probes further into the data in order to chronicle one of the participants' experiences of study over the course of that semester. Because we were interested in investigating the lived experience of the online learner, the majority of this section is devoted to documenting, through a case study of both survey and interview data, the experiences of one participant, Angela, to provide more insight into online engagement and effective engaging practice. Angela was chosen for a number of reasons: she fits in the demographic profile of many online students, as matureage, in paid employment, and with significant family responsibilities and extracurricular interests, including a holiday planned during semester. Although she did not complete the final surveys, Angela was chosen as our case study because her interviews were rich in detail on the challenges and benefits of 
managing study online alongside significant personal and workplace commitments.

\section{Angela's Semester}

Angela manages part-time study with part-time work in the school education sector. She is married, with adult children who live at home and attend university themselves. Angela began her degree through mutual encouragement by a colleague (her "study buddy") who is also studying online in the same course. Angela self-identified as proactive and a high achiever. At the time of the interviews, Angela had arranged to accelerate her studies, enrolling in three units (75\% load) instead of two (50\%), and had planned a ten-day family holiday around week 10 of semester. It was important to Angela to maintain a balance between her studies and her family life, including time with her husband, such as by taking a holiday together.

Although Angela was anxious about the increased workload, and about the impact of the holiday on her studies, she felt confident about finishing her units because of her organised approach. Angela completed five surveys over the course of the semester, aligning with semester weeks 1, 3, 5, 6 and 9 (Angela was overseas during weeks 10 and 11 of semester, so unable to complete the survey in those weeks). In week 1 she reported an engagement level of 0 , peaked at an engagement level of 8 in week 6, and her final survey in week 9 reported an engagement level of 6 (see Figure 2). 


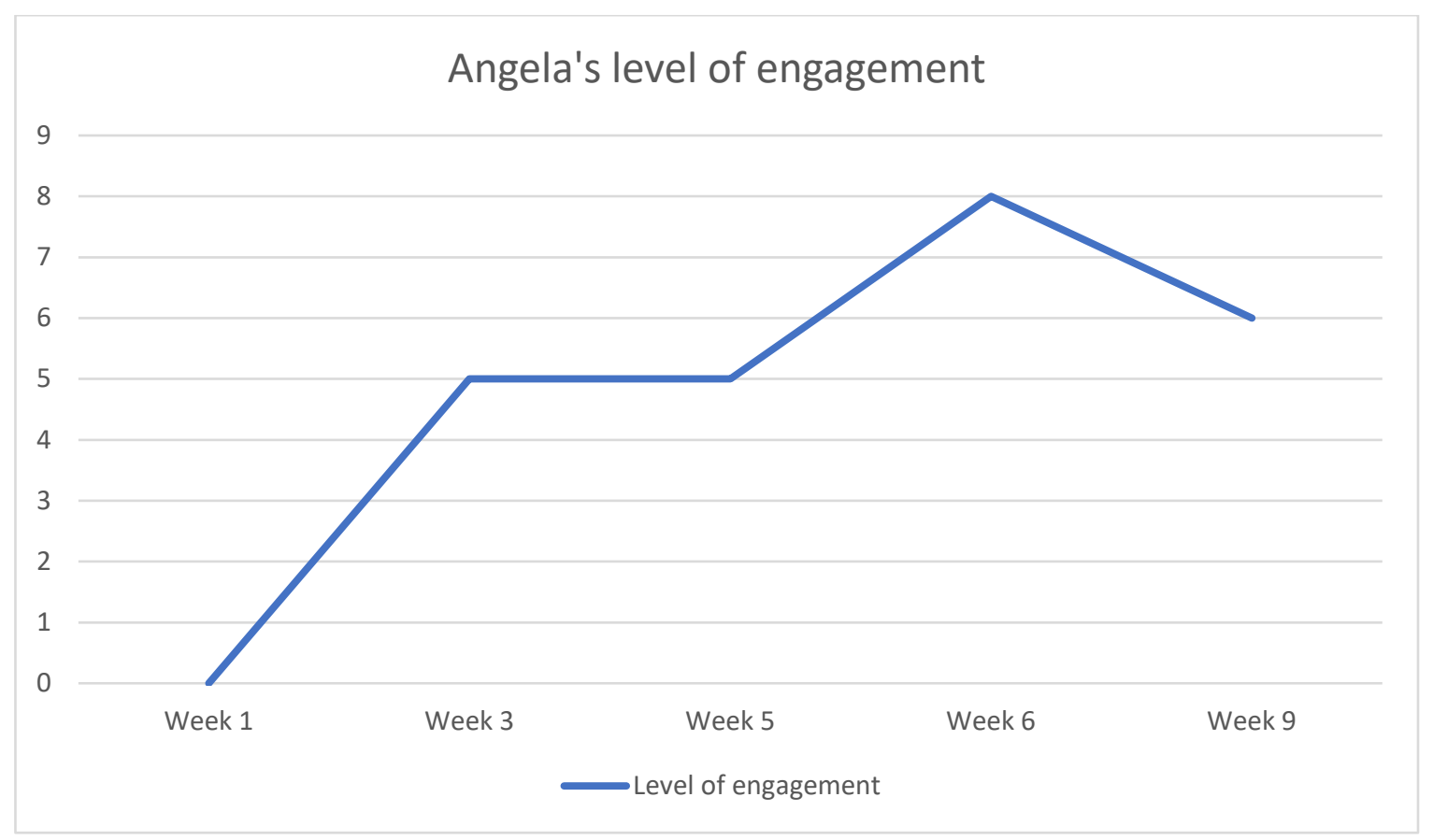

Figure 2. Angela's levels of engagement over the course of the semester

In the pre-semester interview Angela discussed what the coming thirteen weeks entailed, including the increased workload of moving from her usual two to three units. Angela was apprehensive but "cautiously confident” about this move, describing how she was preparing by downloading unit outlines, reading assessment criteria, and planning around assessment due dates. She stated that mature aged students need to be "clever with [...] time [...] cause it's got to fit in with the rest of your life”, highlighting a central theme of her interviews balancing work and life commitments. Angela also identified one of her key support systems: her "study buddy". Angela and her study buddy were purposefully studying the same units at the same time. Studying with a friend was the "best choice”, Angela said, because they could offer mutual support and confidence. During this interview, Angela also discussed her individual perceptions and experiences of online learning. For Angela, being engaged meant a higher quality of work, "go[ing] the extra step": doing "extra reading”, contacting lecturers and tutors personally, and adding "sincere value" to discussion boards rather than "just making comments 'cause I know that's the expectation”. She acknowledged the need for online students to be more selfdisciplined: "the onus is a great deal more on you to be responsible". She expected as much from her lecturers and tutors in return. Viewing learning as a "reciprocal relationship", Angela appreciated when the teaching staff member 
was "not just going through the process", but planning specifically for online learning, including: setting clear expectations; making content fully available non-synchronously; providing exemplars; being themselves engaging in recorded lectures; and being available for contact during non-office hours. Angela's presemester interview revealed a student who was highly motivated to succeed, and cognisant of the challenges, benefits and limitations of online study.

In her second interview, conducted in week 2 of semester, Angela described feeling “overwhelmed” by her increased study load. Two of her units had multiple small assessment tasks spread throughout the semester, so Angela sat down with her study buddy to create a spreadsheet to manage due dates. As we found with many of our participants, Angela did not devote equal time to each unit evenly throughout the semester. In this interview, Angela described spending the most time and energy on one unit because it took more effort (it had "laborious” reading involving unfamiliar, technical language): “I like to get the most complex one [done] otherwise it's just hanging over my head like a dark cloud.” Conversely, another of her units seemed reasonably "simple”, needing less time.

A key theme that emerged in Interview 2 was teacher presence and behaviour. Angela described being engaged by lecturers who showed personality or variety in their lectures: telling a story that personalised the material or themselves ("she wasn’t just a person on a screen”), or making lecture recordings in an unusual location. Lecturers with "boring” lecture delivery, or whose voices were difficult to understand or hear, were "sterile” and disengaging. Engagement was boosted by “catchy, interactive” and practical learning activities, while heavy, theorybased reading was "hard". Angela dwelt upon feeling alienated when one of her lecturers posted feedback to online discussions, naming other students in the group but failing to acknowledge Angela's contribution. While Angela said she was "trying not to take it personally", it was clear that this experience could, if repeated, be highly disengaging.

As she described in Interview 2, interacting with her peers online, particularly in discussion spaces, was less important to Angela. Discussion boards were “superficial”, not engaging or "thought provoking”. Angela found more positive interaction in her offline friendship with her study buddy, but acknowledged that without this she may have wanted more interaction with peers online. 
Interview 3, conducted in week 4, reiterated many points from the previous interview. Angela was working hard to manage the workload, but could see that her attention was unbalanced: one unit had very little workload, while another had "copious" reading and lots of activities. For Angela in this week, the readings were a key theme: "long, laborious readings” dominated her study schedule but were disengaging, particularly if written in technical "jargon”. Obversely, one assigned reading that helped her see "the big picture" was "fantastic", prompting interactivity with the textbook itself: she described "highlights [...] and Post-It notes everywhere because it just really consolidated what I knew.”

Angela's third interview shows how the same essential activity (reading an assigned text, or posting to the discussion board) can be either engaging or disengaging. Angela described vividly her disappointment when lecturers didn’t respond to her posts: "you draft it and correct it and get it right and put it up, and then sometimes you just get nothing back and you think, 'Oh geez'”. She also noted her satisfaction in seeing the "little red dot" in the corner of the LMS webpage, notifying her of the lecturer's real-time feedback. This suggests that teacher presence is as important - if not more so - than the design of the activity or task itself. While she prized teacher interactivity, Angela didn't strongly desire peer-to-peer interactivity, because of her "study buddy". She repeated her feeling that online discussion boards were "a means to an end":

I could see [...] the lecturer needs some way of gauging our involvement, our engagement and our understanding, but myself personally if I didn't have to post things or I didn't have to engage other students it wouldn't be detrimental to my learning." (Interview 3)

In her fourth interview, in week 6 of semester, Angela was more "anxious": it was getting close to assessment time for many units and she was recovering from the disappointment of receiving a poor quiz grade. This event prompted Angela towards more focused comments about assessment: including design, instructions, and expectations. Angela identified those units which had been designed with online learners in mind: learning materials were fully accessible from day one; students could move at their own pace; there was clarity in situating the materials and forward-planning in directions for assessment tasks; and compulsory activities were not time-bound. It was those units that she found most engaging. Interview 4 (week 6) corresponds with Angela's peak in self- 
reported engagement, as shown in Figure 2. In her interview she described working hard on assessments, even "up at 2 in the morning for five hours [...] writing like no one’s business”.

Angela commented frequently on asynchronous flexibility, prizing the freedom to move at her own pace: to "zoom ahead" (Interviews 3, 5, 6, 7) or to take a break from study. "Zooming ahead” meant strategically accessing course content ahead of time (lectures, discussion posts) while maintaining focus on major assessment tasks. As Angela described in detail in her fifth interview, for many students assessments are both the main "focus" of work as well as the major distraction from engagement:

I definitely lose balance while I'm focusing [on assessment] and really just do minimal work [...] and then move on. I just feel like [...] it's the assessments that are going to help me pass.

[...] I think from weeks, let's say, 1 to 5 where there's no assessments [...] you give the lectures [and] readings a lot of time, a lot of thought. [But ...] the closer it gets to assessment and the weeks of assessment, it may go from like 16 people answering to 3. (Interview 5)

This was a common theme for our participants: engagement with content and peers is mediated by proximity to assessment due dates.

Interviews 6 (week 9 of semester) and 7 (week 11) framed Angela's overseas holiday, and dwelled on the issue of asynchronous flexibility: the ability to fit study around other life commitments, and the frustration at not being permitted to do so, because of either unit design or lecturer behaviour. Angela wanted to be able to "go at the speed you want" through the content and mechanised assessments such as quizzes (Interview 6). In Interview 6 she described accessing the week 10 content in one of her units, to ensure she had completed the minimum engagement requirements prior to going on holiday. She wanted to be “clever with time” (Interview 7) but felt frustrated by temporal constraints placed on the material: "I feel like I'm working with my hands tied behind my back. [...] the whole point of doing distance study [is] that it's got to be flexible.” (Interview 6) Angela's exasperation chimes with the literature on flexibility, which emphasises students' desire to interact with material asynchronously. 
In her post-semester interview Angela summarised key points of discussion shared throughout the semester. She was ambivalent about discussion boards, seeing them as a "double edged sword”: potentially useful for encountering new ideas, but also "laborious". She reiterated her feeling that having materials and content available from the start of the semester was paramount for allowing her to engage fully with her learning: Angela wanted to be "organized and [...] proactive”, "chipping away at things slowly”. Temporal restraints on access were Angela’s “biggest gripe”. Moreover, as a comment prompted by our interviewer revealed, temporal restraints affected Angela's decision about how many units to enrol in:

Interviewer: If you could be guaranteed that all the units would be like the one where the content was just there ready, [...] would that have affected your decision about doing four?

Angela: Yes. Yes, because while the assessment is immense, [...] knowing I could get through things week to week [...]. It would have swayed me, because that would have cut down my degree by a year. (Interview 8)

\section{Discussion}

The survey results and Angela's interviews share common themes: work-life balance and the priorities of life commitments for online learners; managing assessment and weekly workload, including the overwhelming early weeks; teacher presence; and relevance/interactivity of learning tasks. Survey comments showed that students associated engagement with online interactions, such as contributing to online discussion boards. A number of students mentioned that they were 'not as engaged' since they had assessment tasks due. There was a tendency to 'sacrifice' engagement in one unit to focus on others, in order to meet assessment requirements. It could be argued that students' attention to assessment tasks was evidence of the engagement dimension of academic challenge (Kuh, 2001) as they were required to devote considerable time and effort in order to complete the tasks successfully. Students' interpretations of their levels of engagement support the view that engagement is indeed multifaceted (Fredericks, et al., 2004): it can occur along a continuum (Robinson \& Hullinger, 2008), and individuals differ in their constructs of engagement. 
Interaction with learning content, lecturers and peers was significant throughout the survey data and Angela's interviews. Students appreciated active and collaborative learning (Kuh, 2001), although peer interaction through discussion boards was not as highly valued as student-faculty interaction (Kuh, 2001). Like the online students in Ragusa and Crampton's (2018) study, these students valued quality, timely feedback. Similarly, lecturers and subjects that stimulated interest (Park \& Choi, 2009) were reported as having a positive effect on engagement. Angela praised a unit that provided multiple interactive activities instead of theoretical readings on the topic, as modelling an alternative pedagogical technique she could put in her teaching "backpack" (Interview 2). She also described many instances of disengagement when she perceived her teachers to themselves be disengaged: for example, if they failed to reply to her in the discussion forum. While students generally perceived contribution to discussion boards as indicating engagement, Angela's narrative suggests that many students may only be engaging thus superficially. Angela's interviews show that it is the presence and behaviour of the lecturer, rather than peers, which is key to student engagement online (Stone et al., 2016).

Angela repeatedly emphasized organisation, clarity, and flexibility, appreciating clear instructions, timely communication, and study guides to the materials. She praised units which allowed her to move at her own pace, and was infuriated by those that imposed what she saw as arbitrary temporal limits. Clear expectations emerged as a key issue related to time management, for more than one of our interview subjects, as Angela expressed: "it can become really frustrating and easy to become overwhelmed when you're not getting distinctive information, when everything's a little bit vague” (Interview 7). The reverse side of the need for forward planning on the teachers' side, as Angela identified (Interviews 1, 8), was that successful learning online occurs when the student is prepared, dedicated, self-motivated and has good support (from friends, colleagues and partners). This finding is consistent with other research which identifies family and support as factors in influencing online engagement (Park \& Choi, 2009; Stone et al., 2016).

As a mature-aged woman, married with adult children, studying part-time and working in paid employment, Angela can be considered demographically representative of a significant proportion of online undergraduate students at Australian universities. This 'balancing act' between study and family 
responsibilities often results in guilt, sacrifice and stress, along with interruptions to study progress (Stone \& O'Shea, 2013). Angela is also representative of the many online, mature-age students who set high aspirations and have high expectations. Many of these students work with great dedication, finding "pride and satisfaction from grades, from achieving milestones” (Kahu, Stephens, Leach, \& Zepke, 2015). Angela is no exception.

Our results show that the factors which impacted students' engagement with their units over a semester included: workload across units; assessment tasks; the nature of the units (including delivery and relevance); the presence of, and relationship with, the lecturer; and other life commitments. These findings are consistent with the research literature (e.g., Stone et al., 2016). Peer interaction through forums such as discussion boards was not identified as a strong factor impacting upon engagement, and technology was not seen as a particular barrier, which is in contrast to findings in some other studies (e.g., Yoo \& Huang, 2013). The results show that fluctuating levels of engagement were attributable to competing demands, such as concurrent deadlines and life commitments outside of university study. As Wimpenny and Savin-Baden (2013) found, an academic's style and approach can adversely affect student engagement, leading to recommendations for lecturers and tutors to be clear about their roles and level of interaction with students from the outset, in order to manage a range of expectations.

\section{Conclusions and recommendations}

Understanding the factors that influence student engagement online has strong potential benefits for improving educational outcomes, including retention and completion times. This is of significant importance for regional universities, whose cohorts are more likely to struggle and have higher attrition. Through a longitudinal research methodology this study captured a more nuanced picture of the sustained impact of known factors on student engagement over time, including students' self-management of high workloads, teacher presence and relationship, and work-life balance. While the students in this study experienced similar learning approaches, their accounts varied, indicating the presence of persistence and resilience. This could be an area for future research, whereby students' persistence and resilience to continue despite experiencing feelings of drudgery or alienation (Wimpenny \& Savin-Baden, 2013) could be investigated. 
The results of this study could be useful for course coordinators and administrators seeking to redesign rules, policies and institutional expectations with online students in mind. With this in mind, we offer the following recommendations for lecturers and instructors wishing to improve outcomes for their students.

- Where possible, make learning materials fully accessible at the beginning of semester, to allow students to move at their own pace through content

- Ensure your unit is clearly mapped and logically sequenced

- Try to respond at least once a week to all students, even if it’s just to acknowledge their post

- Avoid making compulsory activities time-bound

In particular, the results of this study provide a timely reminder of the importance of forward planning, design, and teacher presence in successfully engaging the online learner. It is hoped that the findings from this study, and particularly the insights gained from Angela's experience, can be used to inform and improve online teaching, resulting in enhanced online engagement.

\section{References}

Bolliger, D., \& Wasilik, O. (2009). Factors influencing faculty satisfaction with online teaching and learning in higher education. Distance Education, 30(1), 103116.

Boton, E. C., \& Gregory, S. (2015). Minimizing attrition in online degree courses. Journal of Technology and Human Interaction, 5(4), 37-61.

Cohen, L., Manion, L., \& Morrison, K. (2011). Research methods in education (7th ed.). New York: Routledge.

Crawford, R., \& Jenkins, L. (2017). Blended learning and team teaching: Adapting pedagogy in response to the changing digital tertiary environment. Australasian Journal of Educational Technology, 33(2), 51-72. doi:10.14742/ajet.2924 
Creswell, J. W. (2012). Educational research: Planning, conducting, and evaluating quantitative and qualitative research (4th ed.). Boston, MA: Pearson Education.

Department of Education and Training (DET). (2017a). Completion Rates of Higher Education Students - Cohort Analysis, 2005-2014. Canberra: Australian Government. Retrieved from https://docs.education.gov.au/documents/completion-rates-higher-educationstudents-cohort-analysis-2005-2014.

DET. (2017b). Higher Education Statistics - Student Data. Canberra: Australian Government. Retrieved from https://www.education.gov.au/student-data.

DET. (2018). Higher Education Standards Panel Final Report - Improving retention, completion and success in higher education. Canberra: Australian Government. Retrieved from https://docs.education.gov.au/documents/highereducation-standards-panel-final-report-improving-retention-completion-andsuccess

Devlin, M., \& McKay, J. (2016). Teaching students using technology:

Facilitating success for students from low socioeconomic status backgrounds in Australian universities. Australasian Journal of Educational Technology, 32(1), 92-106.

Fredericks, J., Blumenfeld, P. C., \& Paris, A. H. (2004). School engagement: Potential of the concept, state of the evidence. Review of Educational Research, 74(1), 59-109.

Gannon Cook, R., Ley, K., Crawford, C., \& Warner, A. (2009). Motivators and inhibitors for University faculty in distance and e-learning. British Journal of Educational Technology, 40(1), 149-163.

Greenland, S. J., \& Moore, C. (2014). Patterns of student enrolment and attrition in Australian open access online education: A preliminary case study. Open Praxis, 6(1), 45-54. 
Hatch, A. (2002). Doing qualitative research in education settings. Albany, NY: State University of New York Press.

Hewson, E. R. F. (2018). Students' emotional engagement, motivation and behaviour over the life of an online course: Reflections on two market research case studies. Journal of Interactive Media in Education, (1), art. 10, 1-

13. https://doi.org/10.5334/jime.472

Hollway, W., \& Jefferson, T. (2000). Doing qualitative research differently: Free association, narrative and the interview method. London: Sage.

Ilgaz, H., \& Gülbahar, Y. (2015). A snapshot of online learners: E-readiness, esatisfaction and expectations. International Review of Research in Open and Distributed Learning, 16(2), 171-187.

Kahu, E. R. (2013). Framing student engagement in higher education. Studies in Higher Education, 38(5), 758-773.

Kahu, E., Stephens, C., Leach, L., \& Zepke, N. (2015). Linking academic emotions and student engagement: Mature-aged distance students' transition to university. Journal of Further and Higher Education, 39(4), 481-497.

Kuh, G. (2001). Assessing what really matters to student learning. Change, 33, $10-17$.

Lambrinidis, G. (2014). Supporting online, non-traditional students through the introduction of effective e-learning tools in a pre-university tertiary enabling programme. Journal of Higher Education Policy and Management, 36(3), 257267.

Martin, F., \& Bolliger, D. U. (2018). Engagement matters: Student perceptions on the importance of engagement strategies in the online learning environment. Online Learning, 22(1), 205-222.

Michael, K. (2012). Virtual classroom: Reflections of online learning. CampusWide Information Systems, 29(3), 156-165. 
Moore, M. J. (1993). Three types of interaction. In K. Harry, M. John, \& D.

Keegan (Eds.), Distance education theory (pp. 19-24). New York: Routledge.

Park, J. H., \& Choi, H. J. (2009). Factors influencing adult learners' decision to drop out or persist in online learning. Educational Technology and Society, 12(4), 207-217.

Pekrun, R., \& Linnenbrink-Garcia, L. (2012). Academic emotions and student engagement. In S. L. Christenson, A. L. Reschly, \& C. Wylie (Eds.). Handbook of Research on Student Engagement (pp. 259-282). Boston, MA: Springer US.

Ragusa, A. T., \& Crampton, A. (2018). Sense of connection, identity and academic success in distance education: Sociologically exploring online learning environments. Rural Society, 27(2), 125-142. doi:DOI:

10.1080/10371656.2018.1472914

Riessman, C. (2008). Narrative methods for the human sciences. London: Sage.

Robinson, C. C., \& Hullinger, H. (2008). New benchmarks in higher education: Student engagement in online learning. Journal of Education for Business, 84(2), 101-108.

Signor, L., \& Moore, C. (2014). Open Access in Higher Education: Strategies for Engaging Diverse Student Cohorts. Open Praxis, 6(3), 305-313.

Stone, C. (2017). Opportunity through online learning: Improving student access, participation and success in higher education. Curtin University, Australia: National Centre for Student Equity in Higher Education. Retrieved from https://www.ncsehe.edu.au/publications/opportunity-online-learningimproving-student-access-participation-success-higher-education/

Stone, C., \& O’Shea, S. (2013). Time, money, leisure and guilt - the gendered challenges of higher education for mature-age students. Australian Journal of Adult Learning, 53(1), 95-116.

Stone, C., O’Shea, S., May, J., Delahunty, J., \& Partington, Z. (2016).

Opportunity through online learning: Experiences of first-in-family students in 
online open-entry higher education. Australian Journal of Adult Learning, 56(2), 146-169.

Vincenzes, K. A., \& Drew, M. (2017). Facilitating interactive relationships with students online: Recommendations from counselor educators. Distance Learning, 14(4), 13-22.

Wimpenny, K., \& Savin-Baden, M. (2013). Alienation, agency and authenticity: A synthesis of the literature on student engagement. Teaching in Higher Education, 18(3), 1-16 doi:10.1080/13562517.2012.725223

Yoo, S. J., \& Huang, W. D. (2013). Engaging online adult learners in higher education: Motivational factors impacted by gender, age, and prior experiences. The Journal of Continuing Higher Education, 61(3), 151-164. 